\title{
Inquiry-Based Learning through the Creative Thinking and Expression in Early Years Education
}

\author{
Aikaterini Michalopoulou \\ Department of Early Years Education, University of Thessaly, Thessaly, Greece \\ Email: kmihal@uth.gr \\ Received 17 January 2014; revised 17 February 2014; accepted 24 February 2014 \\ Copyright (C 2014 by author and Scientific Research Publishing Inc. \\ This work is licensed under the Creative Commons Attribution International License (CC BY). \\ http://creativecommons.org/licenses/by/4.0/ \\ (c) (j) Open Access
}

\begin{abstract}
Many different skills make up inquiry-based learning for children, and children need many opportunities to develop and use these skills as they progress through the Kindergarten years. Inquiry skills should not be taught in isolation, but integrated into interesting topics and ideas. Children need many opportunities to generate and discuss ideas, make plans, brainstorm solutions to problems, reflect and give reasons for their choices. The aim of the research conducted at kindergartens in Volos, is to explore pre-school age children's responses, thoughts, ideas and feelings through pictures of art. Our study involved asking children to study paintings and create opportunities for them to express their ideas through a wide range of types of representation. Creative expression influences children's growing competence as creative problem solvers.
\end{abstract}

\section{Keywords}

Creativity, Imagination, Art, Investigation, Inquiry, Curriculum, Early Years

\section{Introduction}

Early Years Education's curriculums can capitalize on children's natural curiosity and their desire to make sense of their environment. However, curiosity on its own is not enough. The guidance of the preschool teacher is essential to enable children to learn through inquiry.

Creative thinking and expression is an important component of children's early learning experiences. Children who are given opportunities to develop their imagination and creativity through a variety of media are learning to express their individuality in interests, abilities and knowledge. Creative education involves a balance between teaching knowledge and skills, and encouraging innovation (NACCCE, 1999). Creativity is a key, 
cross-curricular thinking skill, which has implications for our future society.

The main direction of research into creativity in the 1990s has been to contextualize it in a social psychological framework which recognizes the important role of social structures in fostering individual creativity (Jeffrey \& Craft, 2001). The overall results from these researches have suggested that in a creative climate, the participants in the organization:

- feel challenged by their goals, operations and tasks;

- feel able to take initiatives and to find relevant information;

- feel able to interact with others;

- feel that new ideas are met with support and encouragement;

- feel able to put forward new ideas and views;

- experience debate within an open environment;

- feel uncertainty is tolerated and thus risk-taking is encouraged (Craft, 2002).

\section{Inquiry-Based Learning}

Investigations involve attempts, by the class or a group of children, to find answers to questions/problems either raised by the children themselves at various stages of the learning process or proposed by the teacher and adopted by the children. They may stem from the need to collect additional information, in order to supplement their knowledge, or to experiment in order to test ideas, hypotheses and questions arising during free play sessions, during group discussions, or on other occasions, such as a visit or a current event. Creative expression influences children's growing competence as creative problem solvers and provides insight about the world around them.

Investigations are a suitable framework for learning because young children have an innate curiosity, formulate perceptive questions and display keen interest in the world around them. They explore their environment in various ways: observing shapes and colours, movements, events and natural phenomena. They group and compare, recognize properties that are shared or different. They listen, sample, smell and touch. They express themselves in various ways. They try to test out new things, to solve "problems" (Christidou, 2008).

Nevertheless, curiosity does not automatically lead to learning. Children's spontaneous desire to explore is reinforced by the teacher when she encourages the children to ask questions and think, providing them with opportunities to plan, observe, collect, process and interpret data, to reach and present conclusions. The teacher must broaden the child's horizons, expanding those horizons to take in new and meaningful experiences. In this way the children are initiated into the basic skills of the investigative process, and gradually begin to carry out more methodical inquiries (Michalopoulou, 2012).

\section{Curriculum and Creativity}

Young people should find their learning challenging, engaging and motivating. The curriculum should encourage high aspirations and ambitions for all, should be support to enable children to sustain their effort. For creative development the early years curriculum encompasses art, craft and design, and various form of dramatic play and creative expression, all of which have traditionally formed a core part of early years provision (Craft, 2002). Within creative development, creativity is linked with other early learning processes, such as play, art and design.

Teachers support creative learning by providing experiences that encourage children to use their imagination and to experiment with new ideas and materials. When they view others' work, children are also learning to appreciate and respect differences in culture and viewpoint (Michalopoulou, 2008). In all such activities, however, the focus should be on exploration and creativity, to allow children to develop individual skills and self-confidence. Children need many opportunities to generate and discuss ideas, make plans, brainstorm solutions to problems, reflect and give reasons for their choices. Children's creativity must be extended by the provision of support for their curiosity, exploration and play. They must be provided with opportunities to explore and share their thoughts, ideas and feelings, for example, through a variety of art, music, movement, dance, imaginative and role-play activities, mathematics, and design and technology (Victorian Early Years Learning and Development Framework, 2009).

But what creative development means for children?

- Creativity is about taking risks and making connections and is strongly linked to play. 
- Creativity emerges as children become absorbed in action and explorations of their own ideas, expressing them through movement, making and transforming things using media and materials such as crayons, paints, scissors, words, sounds, movement, props and make-believe.

- Creativity involves children in initiating their own learning and making choices and decisions.

- Children's responses to what they see, hear and experience through their senses are individual and the way they represent their experiences is unique and valuable.

- Being creative enables children to explore many processes, media and materials and to make new things emerge as a result (Victorian Early Years Learning and Development Framework, 2009).

The placing of creativity more centrally in the early years curriculum in Greece (Pedagogical Institute, 2011) during the last significant curriculum changes in the early years sector, has not yet been implemented, despite a growing recognition of the need to ensure that creativity is fostered in learners and teachers.

\section{The Research}

The aim of the research conducted at kindergartens in Volos, is to explore pre-school age children's responses, thoughts, and ideas through pictures of art. Our study involved asking children to study paintings and create opportunities for them to express their ideas through a wide range of types of representation.

Creativity is central to the arts and through their rich diversity unlimited possibilities and unique opportunities for its development are available (Prentice, 2000).

\subsection{The Hypothesis. The Sample}

The hypothesis we formulated is that children's responses, thoughts and ideas through pictures of art diversify with the picture of art. The research was conducted with 32 children aged 4.5 to 6.5 attending two Kindergartens in Volos. All children come from a middle-class socioeconomic level.

\subsection{Research Tools}

We choose eight pictures of art without colours, as shown in Figures 1-8 and three pictures of art with colours, as shown in Figure 9, Figure 10 and Figure 11. Children were asked what they think the artist has painted for each figure separately. They also were asked to draw whatever they preferred from the pictures of art.

A. Pictures of art without colours:

B. Pictures of art with colours:

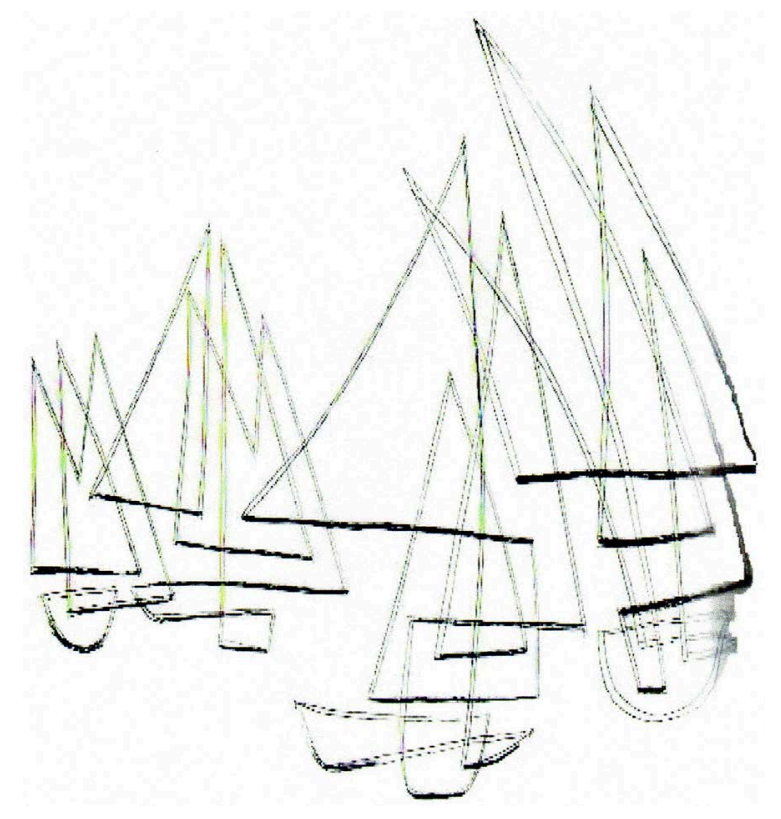

Figure 1. Sailing boat (P. Klee). 


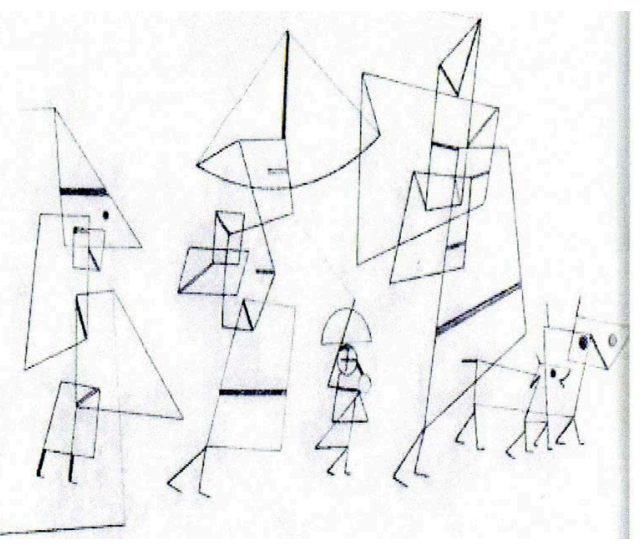

Figure 2. The way out (P. Klee).

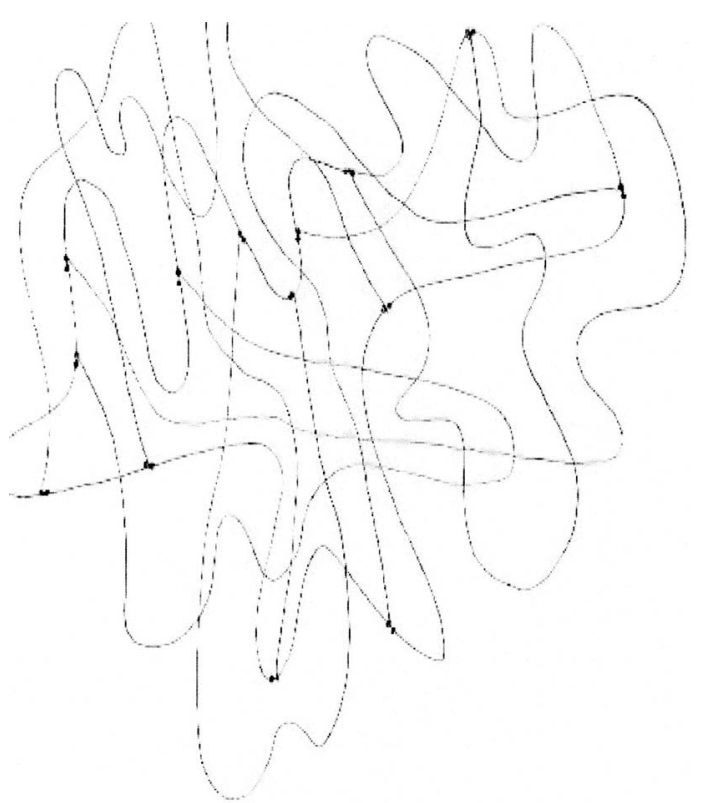

Figure 3. Polyphonic synthesis (P. Klee).

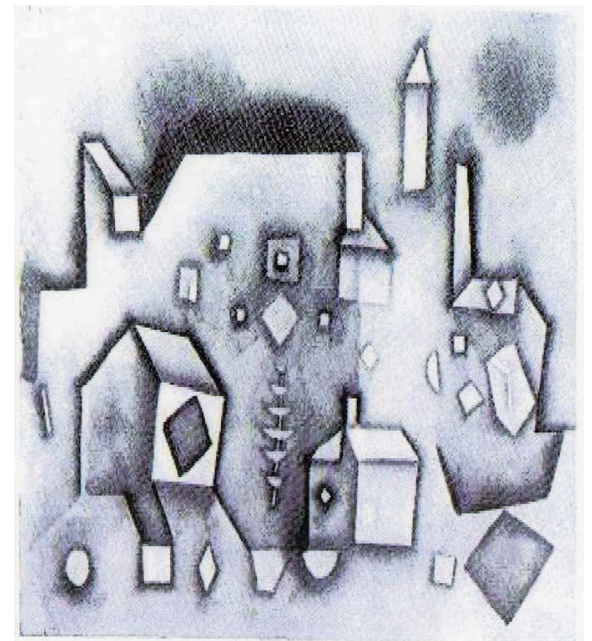

Figure 4. A village (P. Klee). 


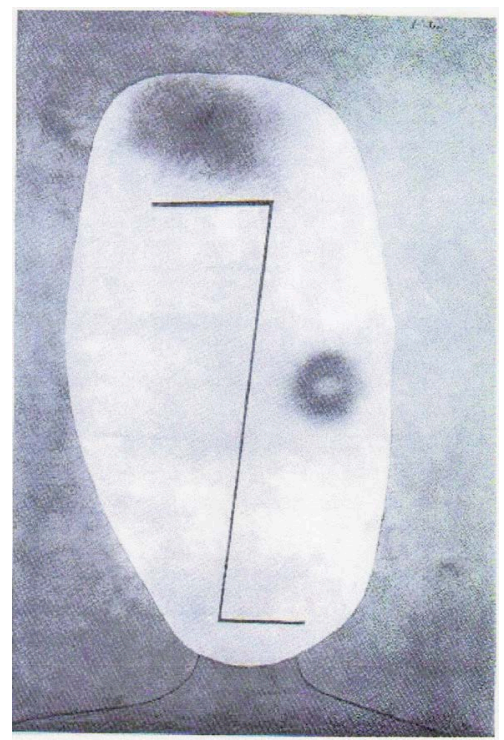

Figure 5. Mr. Z (P. Klee).

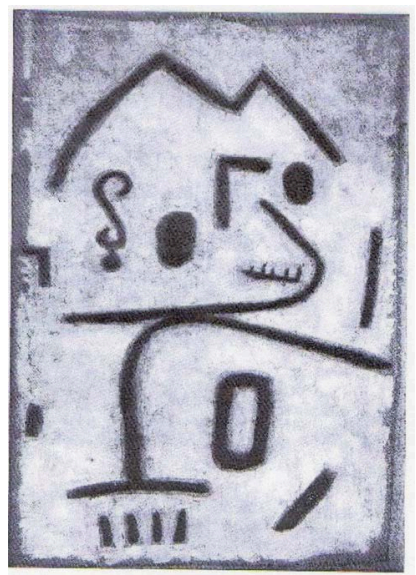

Figure 6. A monument (P. Klee).

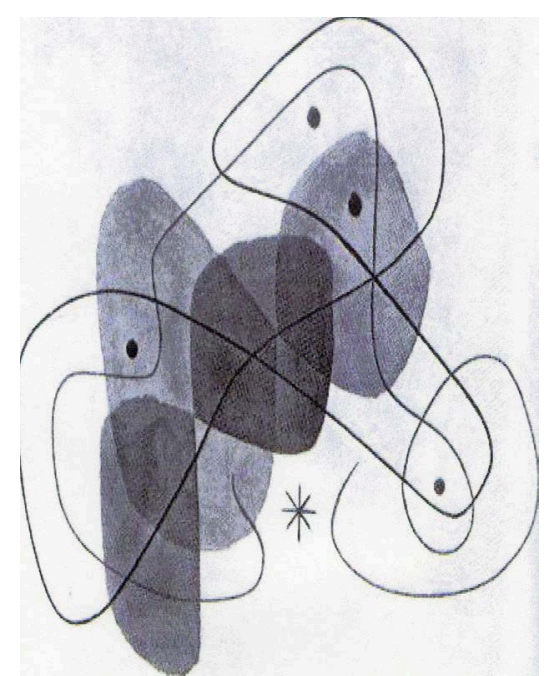

Figure 7. Polyphonic movement (P. Klee). 


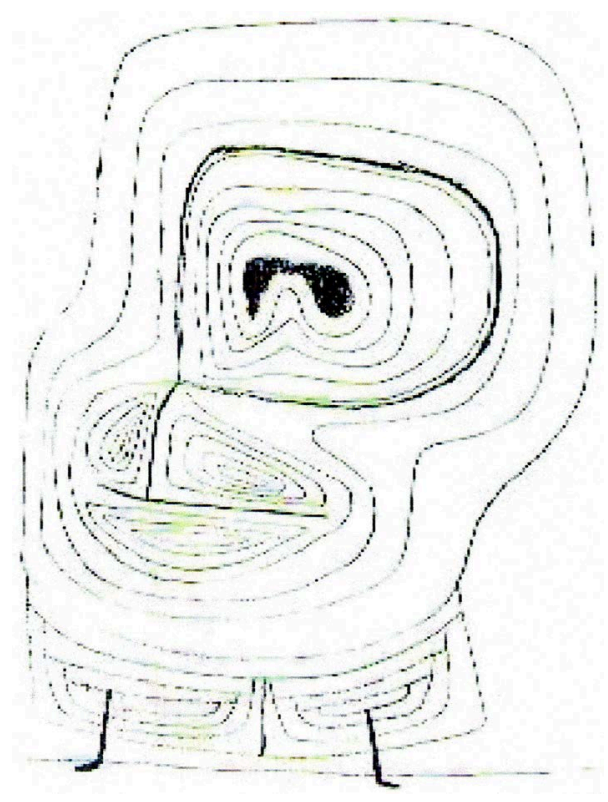

Figure 8. Pregnancy (P. Klee).

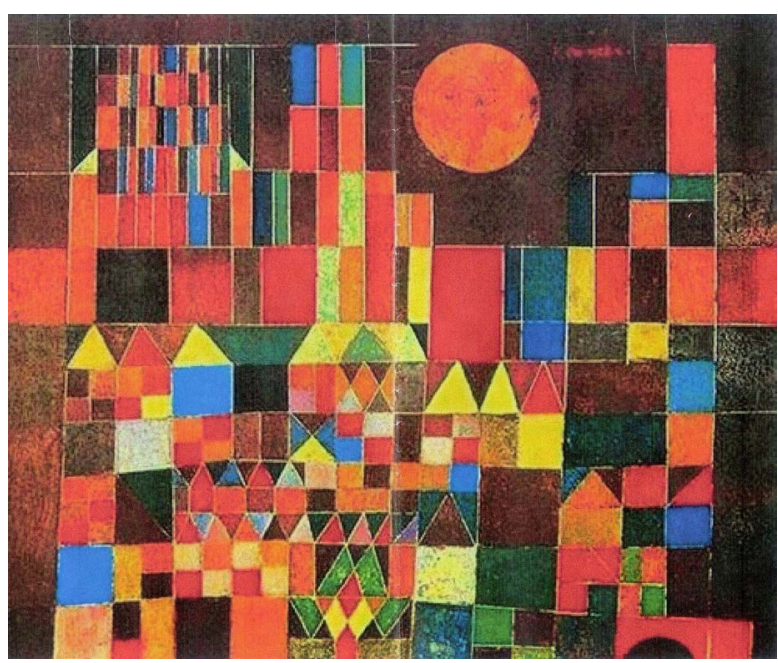

Figure 9. Houses (P. Klee).

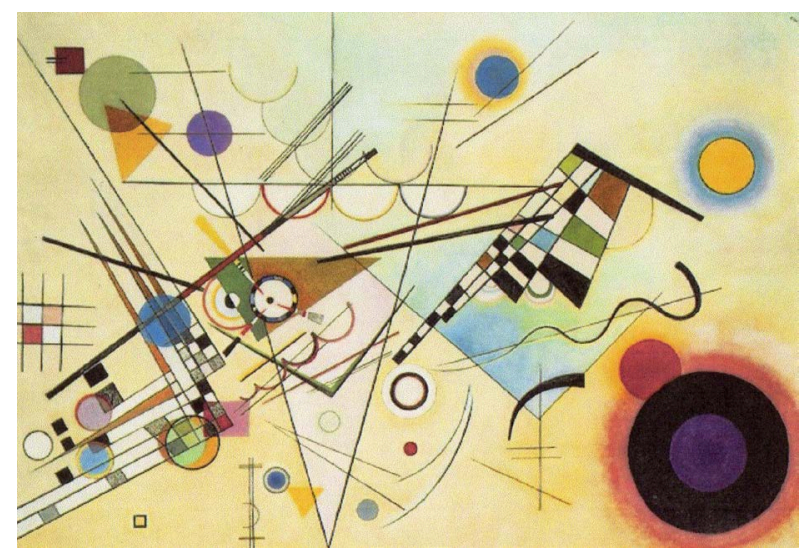

Figure 10. Drawing with corners (B. Kandinsky). 


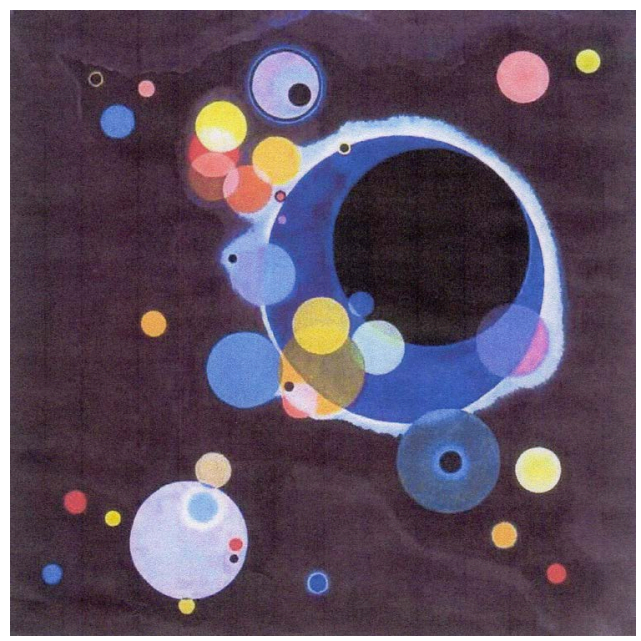

Figure 11. Circles into a circle (B. Kandinsky).

\subsection{Results}

- In their drawings, children in a way try to imitate the way that the picture of art is designed, as shown in Figure 12 and Figure 13, where they imitate the Figure 9.

- At the same time, children are creative by thinking of new ideas and ways of doing things, as shown in Figure 14 and Figure 15, where they represent Figure 10 and Figure 11.

- In their answers at the question "What do you think the artist has painted?", children gave completely different meanings.

The fact that the pictures belong to the abstract art encouraged children to create very different meanings. For example, the picture "Sailing boat" of P. Klee, as shown in Figure 1, had the following meanings: triangles, sail, boxes, people, kites, cavaliers, a little girl, houses, a dog, ants, stars, lines, houses with people. The picture "The way out”, as shown in Figure 2, had the following meanings: people, children, little dogs, stars, columns, figures. The picture "Polyphonic synthesis", as shown in Figure 3, had the meanings: birds, people who are dancing, wire, roads, a smudge, wind, plants, water. The picture "A village", as shown in Figure 4, had the meanings: houses, a town, little houses, buildings, birds. The picture "Mr Z", as shown in Figure 5, had the meanings: Zorro, the letter Z, a number, a man, a potato, a chandelier, an illuminating shell, a door, the moon. The picture "A monument", as shown in Figure 6, had the meanings: a baby, a puzzle, herbs, glasses, a cartoon, drawing of houses, a photo, a duck. Furthermore, the picture "Polyphonic movement" of P. Klee as shown in Figure 7, had the following meanings: a balloon, a labyrinth, a road, a kingdom, a ghost, a computer, a television, a refrigerator, a monster, the sea, a river, a whale, people, a girl. Finally, the picture "Pregnancy", as shown in Figure 8, had the following meanings: a head, a monster, roads, lines.

\section{Conclusion}

Creative work is important as a teaching approach because children need to understand some things with their emotions and imaginations as well as in cognitive terms. Creativity has no place in the traditional classroom, which is a place of silence, where the discourse of the teacher is mimicked and its authenticity accepted without question. Within this setting the creative child is often seen as a threat to discipline. He asks too many questions, and is critical of the teacher.

To ensure that there is enough time for children to express their thoughts, ideas and feelings in a variety of ways, and that children enjoy and maximize opportunities in art, teachers should consider carefully the time they allow for art, how they structure that time and what kind of experience they are offering. Making time for art in a way that offers a meaningful experience involves knowledge of children's development and what motivates them (Robinson, 2002). Art nourishes the unconventional and nurtures the unexpected by respecting children's imagination, developing their creativity, encouraging adventurous thinking and recognizing the validity of a personal response. 


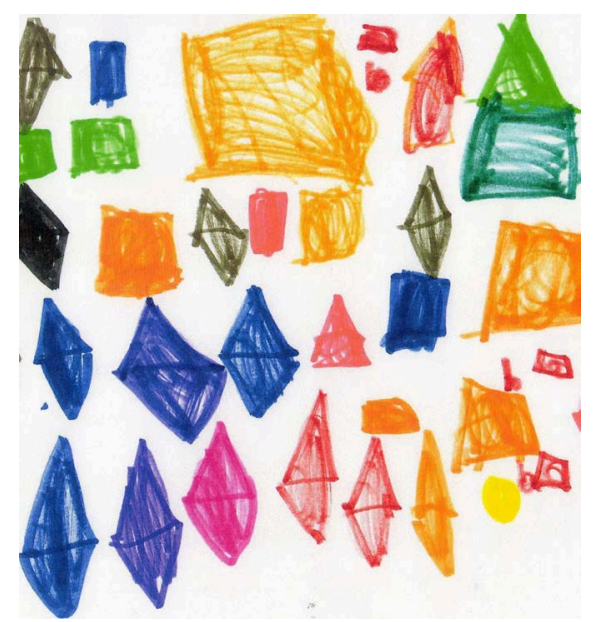

Figure 12. A children's drawing about the picture of art "Houses” (P. Klee).

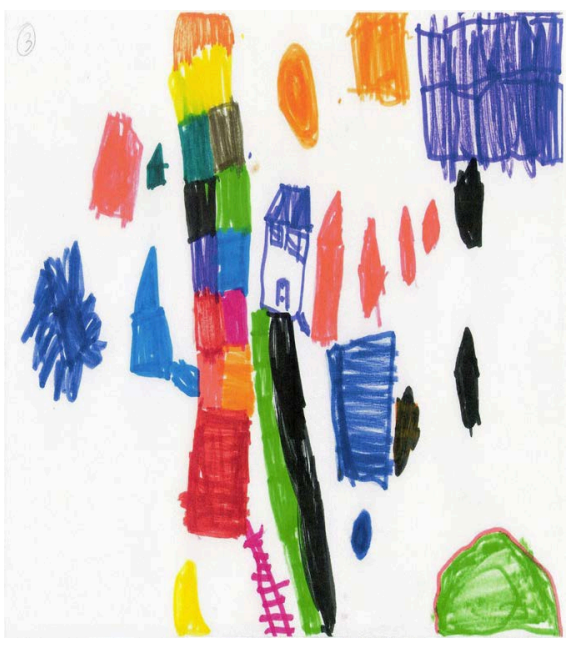

Figure 13. A children's drawing about the picture of art "Houses” (P. Klee).

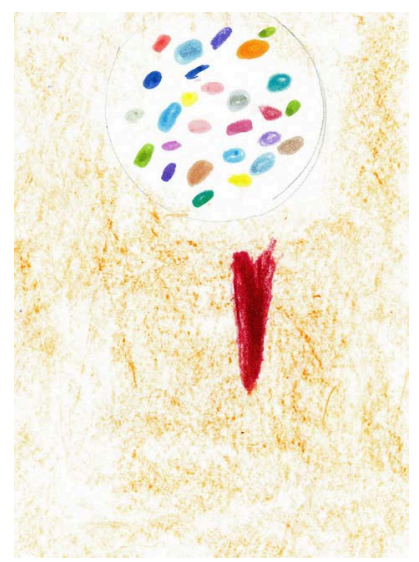

Figure 14. A children's drawing combines elements from the pictures of art "Drawing with corners" and "Circles into a circle" (B. Kandinsky). 


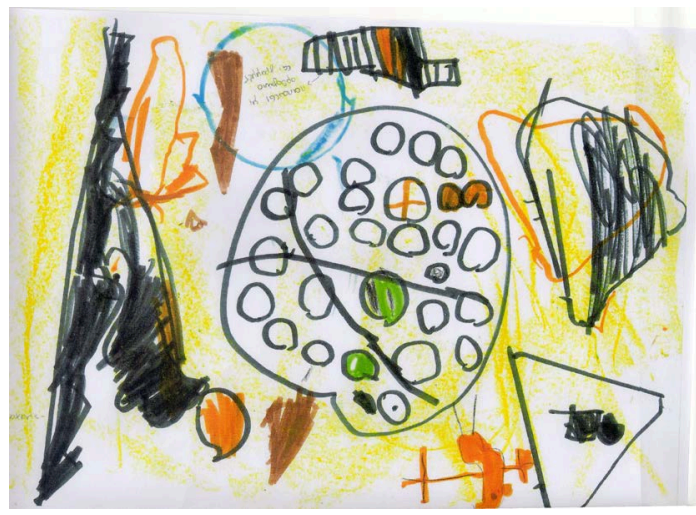

Figure 15. A children's drawing combines elements from the pictures of art "Drawing with corners" and "Circles into a circle" (B. Kandinsky).

Children develop dispositions for learning such as curiosity, cooperation, confidence, creativity, commitment, enthusiasm, persistence, imagination and reflexivity, when they participate in a variety of rich and meaningful inquiry-based experiences, persevere and experience the satisfaction of achievement, persist even when they find a task difficult.

\section{References}

Christidou, V. (2008). Introducing Children in Sciences. Thessaloniki: Kyriakidis. (in Greek)

Craft, A. (2000). Creativity across the Primary Curriculum. London: Routledge.

Craft, A. (2002). Creativity and Early Creativity and Early years Education. A Lifewide Foundation. London: Continuum.

Jeffrey, B., \& Craft, A. (2001). The Universalisation of Creativity. In A. Crafr, B. Jeffrey, \& M. Leibling (Eds.), Creativity in Education. London: Continuum.

Michalopoulou, A. (2008). The Development of Children’s Aptitude for Comparison in Kindergarten. International Journal of Learning, 15, 219-224.

Michalopoulou, A. (2012). Investigations and Inquiry-Based Learning in the Curriculums of Preschool Education. Proceedings of EDULEARN12 Conference, Barcelona, 2-4 July 2012, 1-6.

National Advisory Committee on Creative and Cultural Education (NACCCE) (1999). All Our Futures: Creativity, Culture and Education. London: Department of Education and Employment.

Pedagogical Institute (2011). Curriculum of Preschool Education. Athens: Pedagogical Institute. (in Greek)

Prentice, R. (2000). Creativity: A Reaffirmation of Its Place in Early Childhood Education. Curriculum Journal, 11, 145-158. http://dx.doi.org/10.1080/09585170050045173

Robinson, G. (2002). Mummy’s Face Is Green! Developing Thinking and Skills in Art. In J. Moyles, \& G. Robinson, Beginning Teaching: Beginning Learning in Primary Education. London: Continuum.

Victorian Early Years Learning and Development Framework (2009). Victorian Early Years Learning and Development Framework for all Children from Birth to Eight Years. Melbourne: Early Childhood Strategy Division. 